\title{
Mycophenolate mofetil for the treatment of autoimmune hepatitis in patients refractory to standard therapy
}

\author{
Shane M Devlin MD FRCPC ${ }^{1}$, Mark G Swain MD FRCPC ${ }^{1}$, Stefan J Urbanski MD FRCPC ${ }^{2}$, \\ Kelly W Burak MD FRCPC ${ }^{1}$
}

SM Devlin, MG Swain, SJ Urbanski, KW Burak. Mycophenolate mofetil for the treatment of autoimmune hepatitis in patients refractory to standard therapy. Can J Gastroenterol 2004;18(5):321-326.

There are limited therapeutic options available for patients with autoimmune hepatitis in whom conventional treatment fails. A case series of five patients unresponsive to or unable to take azathioprine, 6-mercaptopurine or corticosteroids who were treated with mycophenolate mofetil (MMF) is reported. While on MMF, alanine aminotransferase normalized or remained normal in all patients. MMF had a steroid-sparing effect and histological remission was demonstrated in one patient after seven months of MMF. One patient experienced an uncomplicated episode of pyelonephritis. In conclusion, MMF can effectively induce and maintain remission in refractory autoimmune hepatitis patients.

Key Words: Autoimmune hepatitis; Mycophenolic acid; Steroid sparing; Therapy
Le mycophénolate mofétil pour le traitement de l'hépatite chronique active auto-immune chez les patients réfractaires au traitement standard

Les possibilités thérapeutiques sont limitées pour les patients atteints d'hépatite chronique active auto-immune chez qui le traitement traditionnel échoue. On rend compte d'une série de cas de cinq patients réfractaires à l'azathriopine, au 6-mercaptopurine ou aux corticoïdes ou incapables de prendre ces médicaments et qui ont été traités au mycophénolate mofétil (MMF). Pendant que ces patients prenaient du MMF, leur alanine aminotransférase est redevenue normale ou l'est demeurée. Le MMF a un effet d'épargne sur les stéroïdes, et un patient a profité d'une rémission histologique après sept mois sous MMF. Un patient a vécu un épisode de pyélonéphrite sans complication. En conclusion, le MMF peut favoriser et maintenir une rémission efficace chez les patients atteints d'une hépatite chronique active auto-immune réfractaire.

\begin{abstract}
$\mathrm{A}_{\mathrm{d}}$ utoimmune hepatitis (AIH) is a chronic inflammatory disorder of the liver of unknown etiology. It is relatively uncommon; the incidence of type $1 \mathrm{AIH}$ in Europe and North America ranges from 0.1 to 1.9 per 100,000 , and a point prevalence in Northern Europe is 16.9 per $100,000(1,2)$. AIH is associated with significant morbidity and, if untreated, mortality. The disorder accounts for $5.9 \%$ of liver transplants in the United States and, if left untreated, has up to a $40 \%$ six-month mortality for more severe disease $(3,4)$.

Corticosteroids, with or without azathioprine (AZA), have been shown to be effective in inducing and maintaining remission in this disorder and are currently the standard of care (4-8). Remission occurs in $65 \%$ of those affected after 18 months of therapy, and in $80 \%$ after three years of therapy (9). A minority of patients will either be intolerant of or fail conventional therapy. A number of alternative therapies have been studied including cyclosporine (10-15), 6-mercaptopurine (6-MP) (16), cyclophosphamide (17), ursodeoxycholic acid (UDCA) (18), budesonide (19) and methotrexate (20-21). Budesonide, cyclosporine and UDCA are the only therapies that have been formally evaluated in clinical trials $(18-19,22)$.
\end{abstract}

There have been a total of eight patients reported in two studies evaluating the effect of mycophenolate mofetil (MMF) in patients refractory to or unable to take conventional therapy $(23,24)$. We report five patients with classical type $1 \mathrm{AIH}$ who were either intolerant of or failed conventional therapy, who showed biochemical improvement and, in one case, histological improvement with the use of MMF.

\section{CASE PRESENTATIONS}

All patients met the pretreatment diagnostic criteria for definite type $1 \mathrm{AIH}$ according to the International Autoimmune Hepatitis Group (Table 1) (25). All other causes of liver disease were excluded in these patients. Specifically, there was no history of excessive alcohol consumption or use of hepatotoxic substances, and all patients were hepatitis $\mathrm{C}$ antibody negative, hepatitis $\mathrm{B}$ surface antigen negative, antimitochondrial antibody negative, and had normal ceruloplasmin and iron studies. Liver biopsies were performed at the time of diagnosis and were compatible with AIH in all patients. There was no evidence of coexisting primary biliary cirrhosis, primary sclerosing cholangitis, autoimmune cholangitis, hemochromatosis

\footnotetext{
${ }^{1}$ Liver Unit, Division of Gastroenterology; ${ }^{2}$ Department of Pathology, University of Calgary, Calgary, Alberta

Correspondence: Dr Kelly W Burak, University of Calgary Medical Clinic, Room G128 Health Sciences Center, University of Calgary, 3330 Hospital Drive Northwest, Calgary, Alberta T2N 4N1. Telephone 403-210-9363, fax 403-210-9368, e-mail kwburak@ucalgary.ca

Received for publication January 21, 2004. Accepted March 5, 2004
} 
TABLE 1

Patient characteristics at time of initial diagnosis of autoimmune hepatitis

\begin{tabular}{lccccccc}
\hline Case & ANA & ASMA & AMA & IgG & ALT & ALP & $\begin{array}{c}\text { Pretreatment } \\
\text { IAIHG score }\end{array}$ \\
\hline 1 & Neg & $1: 160$ & Neg & 28 & $491^{*}$ & $129^{\ddagger}$ & 17 \\
2 & $1: 640$ & $1: 20$ & Neg & 41.2 & $1195^{\dagger}$ & $462^{\S}$ & 24 \\
3 & $1: 2560$ & Neg & Neg & 28 & $709^{*}$ & $48 \ddagger$ & 20 \\
4 & $1: 640$ & Not known & Neg & 73 & $58^{*}$ & $90 \ddagger$ & 18 \\
5 & $1: 160$ & $1: 50$ & Neg & 11.7 & $829^{\dagger}$ & $455^{\ddagger}$ & 17 \\
\hline
\end{tabular}

AMA Antimitochondrial antibody titre; ALP Alkaline phosphatase ( ${ }^{\ddagger}$ normal range 30-145 U/L; §normal range 80-280 U/L); ALT Alanine aminotransferase ("normal range 0-40 U/L; ${ }^{*}$ normal range 0-65 U/L); ANA Antinuclear antibody titre; ASMA Anti-smooth muscle antibody titre; Ig Immunoglobulin $\mathrm{G}$ (normal 6.8-18.0 g/L). International Autoimmune Hepatitis Group (IAIHG) score greater than $15=$ definite diagnosis of autoimmune hepatitis. Neg Negative

\section{TABLE 2}

Serum alanine aminotransferase (ALT) (U/L) relative to initiation of treatment with mycophenolate mofetil (MMF) (months)

\begin{tabular}{lccccccccccccccc}
\hline Month & $\mathbf{- 6}$ & $\mathbf{- 3}$ & $\mathbf{0}$ & $\mathbf{3}$ & $\mathbf{6}$ & $\mathbf{9}$ & $\mathbf{1 2}$ & $\mathbf{1 5}$ & $\mathbf{1 8}$ & $\mathbf{2 1}$ & $\mathbf{2 4}$ & $\mathbf{2 7}$ & $\mathbf{3 0}$ & $\mathbf{3 3}$ & $\mathbf{3 6}$ \\
\hline${\text { Case } 1^{*}}^{\mathbf{7 4}}$ & $\mathbf{1 5 7}$ & $\mathbf{4 5 3}$ & 33 & $\mathbf{9 1}$ & 33 & 39 & 34 & 39 & $\mathbf{4 4}$ & 30 & & & & \\
${\text { Case } 2^{\dagger}}^{50}$ & 39 & $\mathbf{1 6 8}$ & 44 & $\mathbf{9 4}$ & 55 & 47 & & & & & & & \\
Case $^{*}$ & $\mathbf{3 7 0}$ & $\mathbf{1 6 4}$ & $\mathbf{2 0 4}$ & 28 & 24 & 28 & 32 & 28 & 28 & 26 & 17 & 24 & 20 & 21 & 25 \\
Case $^{*}$ & $\mathbf{5 2}$ & $\mathbf{4 5}$ & $\mathbf{1 1 0}$ & 26 & 17 & 19 & 19 & & & & & & & \\
Case $5^{\dagger}$ & 53 & 36 & 30 & 56 & 33 & 34 & 39 & 28 & & & & & & \\
\hline
\end{tabular}

*normal range: 0-40 U/L; thormal range 0-65 U/L. ALT levels above the upper limit of normal are shown in bold. Time zero corresponds to the initiation of treatment with MMF

or $\alpha 1$ antitrypsin deficiency in any of the biopsies. All patients had a predominately hepatocellular pattern of liver test elevation at the time of diagnosis (Table 1). Two patients had an elevation of alkaline phosphatase at diagnosis; however, the alkaline phosphatase normalized in both patients after treatment for AIH was initiated.

\section{Case 1}

A 65-year-old man with no relevant past medical history was diagnosed with AIH in 1997. Liver biopsy at the time revealed cirrhosis and a plasma cell predominant inflammatory infiltrate (grade 4/4 inflammation, stage 4/4 fibrosis). The patient was initially treated with prednisone $40 \mathrm{mg} /$ day. This resulted in biochemical improvement and the prednisone was tapered to $20 \mathrm{mg} /$ day. Upon tapering, a biochemical flare prompted initiation of $50 \mathrm{mg} /$ day of $6-\mathrm{MP}(0.7 \mathrm{mg} / \mathrm{kg})$ in November 1997. In October 2001, a biochemical flare prompted an increase in the dose of $6-\mathrm{MP}$ to $100 \mathrm{mg} /$ day $(1.4 \mathrm{mg} / \mathrm{kg})$ in addition to $20 \mathrm{mg} /$ day of prednisone. In October 2001, 6-MP was stopped because of continued biochemical and symptomatic deterioration and MMF $500 \mathrm{mg}$ twice daily was started. The dose of MMF was later increased to $750 \mathrm{mg}$ twice daily and the dose of prednisone was successfully decreased to $10 \mathrm{mg} /$ day. The serum alanine aminotransferase (ALT) has remained normal to date (Table 2). On MMF, the patient has been able to taper his prednisone dose from $25 \mathrm{mg} /$ day to $10 \mathrm{mg} /$ day. The prednisone dose was temporarily increased from $10 \mathrm{mg} /$ day to $20 \mathrm{mg} /$ day due to an increase in the ALT, which occurred 21 months after initiating MMF. The ALT has returned to normal and the patient continues on $10 \mathrm{mg} /$ day of prednisone. MMF therapy has been well tolerated with no adverse events.
TABLE 3

Dose of prednisone $(\mathrm{mg} / \mathrm{day})$ relative to the initiation of treatment with mycophenolate mofetil (MMF) (months)

\begin{tabular}{llllllllllllllll}
\hline Month & -6 & -3 & 0 & 3 & 6 & 9 & 12 & 15 & 18 & 21 & 24 & 27 & 30 & 33 & 36 \\
\hline
\end{tabular}

\begin{tabular}{llllllllllll}
\hline Case 1 & 20 & 5 & 25 & 10 & 20 & 20 & 20 & 10 & 10 & $20 *$ & 10
\end{tabular}

Case $2 \begin{array}{lllllll}7.5 & 15 & 15 & 15 & 10 & 10 & 7.5\end{array}$

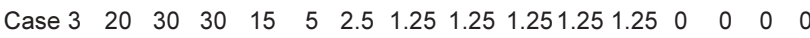

Case $4 \quad 20 \quad 25 \quad 15 \quad 15 \quad 10 \quad 10 \quad 5$

Case $5 \quad 0 \quad 00000000000$

*Case 1 had a slight alanine aminotransferase rise that prompted a brief increase in the dose of prednisone, from $10 \mathrm{mg} /$ day to $20 \mathrm{mg} /$ day. Time zero corresponds to the initiation of treatment with MMF

Case 2

A 58-year-old woman with a history of mild immune thrombocytopenia (ITP) and Sjogren's syndrome was diagnosed with $\mathrm{AIH}$ in August 1997. The patient was initially treated with prednisone $40 \mathrm{mg} /$ day. By October 1997, the serum ALT had normalized on $20 \mathrm{mg} /$ day of prednisone. A liver biopsy was obtained in December 1997 while the patient was on $20 \mathrm{mg} /$ day of prednisone, which revealed grade 2/4 inflammation and stage 2/4 fibrosis consistent with AIH. In February 1998 she suffered a biochemical relapse despite $50 \mathrm{mg} /$ day of prednisone, and AZA $50 \mathrm{mg} /$ day $(1 \mathrm{mg} / \mathrm{kg})$ was initiated. AZA was increased to $100 \mathrm{mg} /$ day $(2 \mathrm{mg} / \mathrm{kg})$ in May 2001 in conjunction with prednisone $15 \mathrm{mg} /$ day. Her ALT then normalized and the prednisone was weaned to $7.5 \mathrm{mg} /$ day until December 2001 when she once again experienced a biochemical flare necessitating increasing her prednisone to $15 \mathrm{mg} /$ day. The serum ALT normalized but on $100 \mathrm{mg} /$ day of AZA and $15 \mathrm{mg} /$ day of prednisone it increased to approximately three times the upper limit of normal (ULN) in May 2002. AZA was then stopped and MMF was started at $500 \mathrm{mg}$ twice daily, corresponding with a normalization of the ALT within two months. In September 2002, the serum ALT increased to 2.5 times ULN and the MMF was increased to $1 \mathrm{~g}$ twice daily. The ALT normalized and the dose of prednisone was successfully decreased to $7.5 \mathrm{mg} /$ day. She continues to take prednisone $7.5 \mathrm{mg} /$ day and MMF $1 \mathrm{~g}$ twice daily. MMF therapy has been well tolerated with no adverse events.

Case 3

A 41-year-old woman with a three-year history of colonic and terminal ileal Crohn's disease presented with abnormal liver enzymes in May 1999. Her Crohn's disease was quiescent, being managed with maintenance 5-aminosalicylic acid. Endoscopic retrograde cholangiography was normal, prompting a liver biopsy, which revealed a periportal plasma cell inflammatory infiltrate consistent with AIH (grade 3/4, stage 2/4). The patient was treated with prednisone $40 \mathrm{mg} /$ day. By January 2000, the serum ALT was normal on $7.5 \mathrm{mg} /$ day of prednisone. In April 2000 the serum ALT increased to nine times ULN while the patient was on $5 \mathrm{mg} /$ day of prednisone. The dose of prednisone was increased to $20 \mathrm{mg} /$ day in conjunction with AZA $100 \mathrm{mg} /$ day $(1.5 \mathrm{mg} / \mathrm{kg})$. Despite a further increase to $30 \mathrm{mg} /$ day of prednisone and $100 \mathrm{mg} /$ day of AZA, the serum ALT failed to normalize by October 2000. At that time, the AZA was discontinued and MMF $250 \mathrm{mg}$ twice daily 
was initiated and soon increased to $500 \mathrm{mg}$ twice daily. Because the serum ALT rapidly normalized the dose of MMF was not increased further. The ALT has remained normal for 36 months with successful cessation of prednisone therapy (Tables 2 and 3). MMF therapy has been well tolerated with no adverse events. The patient's Crohn's disease has remained quiescent to date.

\section{Case 4}

A 62-year-old woman presented in January 2002 with severe thrombocytopenia (platelet count $6 \times 10^{9} / \mathrm{L}$ ) and abnormal liver enzymes. An elevated immunoglobulin $G$ level and a positive antinuclear antibody titre were consistent with AIH (Table 1). Her thrombocytopenia was thought to be due to ITP after a bone marrow biopsy and an evaluation by a hematologist. The patient was initially treated with prednisone $20 \mathrm{mg} /$ day in January 2002. A liver biopsy obtained in March 2002 revealed micronodular cirrhosis, a hepatic venous pressure gradient demonstrating portal hypertension and a plasma cell infiltrate consistent with AIH (grade $2 / 4$, stage 4/4). The thrombocytopenia was likely secondary to a combination of ITP in the setting of hypersplenism secondary to portal hypertension. Given the results of the liver biopsy, the patient was started on $50 \mathrm{mg} /$ day of $6-\mathrm{MP}(0.6 \mathrm{mg} / \mathrm{kg})$ but this was discontinued after a short period of time at the patient's request after repeated episodes of severe epistaxis. The serum ALT failed to normalize on $20 \mathrm{mg} /$ day of prednisone; however, marked weight gain, proximal muscle weakness and cushingoid facies limited dose escalation. Because of the underlying ITP there was initial reluctance to add immunosuppressive agents that could potentially worsen her thrombocytopenia. However, recent evidence supported the use of MMF in the setting of ITP (26). Therefore, in October 2002, MMF $500 \mathrm{mg}$ twice daily was added to prednisone $15 \mathrm{mg} /$ day. The serum ALT normalized and her platelet count increased from a nadir of $6 \times 10^{9} / \mathrm{L}$ before starting MMF to $61 \times 10^{9} / \mathrm{L}$ in February 2003 while on MMF $1 \mathrm{~g} /$ day. The dose of prednisone was decreased from $15 \mathrm{mg} /$ day at the time of initiation of MMF to $5 \mathrm{mg} /$ day. The patient developed Escherichia coli pyelonephritis while on MMF which was successfully treated with intravenous antibiotics in hospital and no other adverse events occurred.

\section{Case 5}

A 44-year-old woman with no past medical history presented in October 2000 with abnormal liver enzymes and right upper quadrant abdominal pain. An abdominal ultrasound revealed cholelithiasis. An endoscopic retrograde cholangiography was performed and was normal. The serum ALT rose to over 5.5 times ULN prompting a liver biopsy and a serological workup for causes of chronic liver disease in December 2000. The liver biopsy revealed expanded portal tracts with plasma cell infiltrates as well as moderate interface hepatitis, but no fibrosis (grade 2/4, stage 0/4). Histological and serological findings were in keeping with AIH. The patient was treated with prednisone $50 \mathrm{mg} /$ day in conjunction with AZA $150 \mathrm{mg} /$ day $(1.3 \mathrm{mg} / \mathrm{kg})$. She then developed incapacitating glucocorticoid-related psychosis and suicidal ideation necessitating the cessation of her prednisone. On dual therapy, her ALT rapidly normalized and subsequently on AZA monotherapy her ALT remained normal although she continued to have fatigue and arthralgias. In November 2001 the patient continued to complain of right upper quadrant pain consistent with biliary colic and was referred for laparascopic cholecystectomy, which was performed in January 2002. A liver biopsy obtained intraoperatively revealed grade 2/4 inflammation and stage 2/4 fibrosis (Figure 1). AZA was discontinued and the patient was started on MMF $1 \mathrm{~g}$ twice daily in June 2002. Because of the disparity between liver biochemistry and histology, a repeat liver biopsy was obtained in January 2003 after seven months of MMF (Figure 2). This biopsy was read by the same pathologist (SJU) as having no significant inflammation and only minimal fibrosis (grade 0/4, stage 1/4). In October 2003 she continued to be in biochemical remission and MMF was successfully reduced to $750 \mathrm{mg}$ twice daily.

\section{DISCUSSION}

A minority of patients with AIH will fail or will be intolerant of conventional medical therapy. Treatment of these patients is problematic due to the consequences of ongoing disease and due to the limited therapeutic options available. The greatest clinical experience in this setting exists with the use of cyclosporine. In addition to many case reports (10-15), there has been one open-label trial evaluating cyclosporine, which demonstrated improved histology and biochemistry over a six-month period (22). The potential for renal toxicity, hyperlipidemia, hypertension and infection are limiting factors concerning the use of this therapy. Cyclophosphamide and methotrexate have shown promise but have only been evaluated in a very small number of patients $(17,20,21)$. UDCA and budesonide are the only other therapies that have been evaluated formally in a prospective fashion $(18,19,27)$. Although UDCA has shown promise as primary therapy in Japanese patients with $\mathrm{AIH}$, a clinical trial evaluating its use in refractory disease failed to demonstrate a significant change in biochemistry or histology $(18,27)$. A pilot study of budesonide in treatment-dependent patients failed to demonstrate efficacy (19).

Mycophenolic acid was first isolated and described in 1946 (28). MMF is an ester prodrug of mycophenolic acid, which acts as a noncompetitive inhibitor of inosine monophosphate dehydrogenase, the rate-limiting enzyme involved in de novo synthesis of purines (29). The drug acts selectively on T and B lymphocytes, which lack adequate salvage pathways for purines (30). The effects of MMF and AZA on purine metabolism had been thought to be similar; however, AZA immunosuppressant properties have recently been attributed to induction of apoptosis of $\mathrm{T}$ cells via suppression of Racl activation (31). This new evidence that these drugs have a different mechanisms of action strengthens the rationale for the use of MMF in patients resistant to AZA. The toxicity profile of MMF includes diarrhea, nausea, vomiting, leukopenia and anemia (30), and may be more attractive than the toxicity profile of cyclosporine.

MMF has been used extensively in the setting of renal, liver and heart transplantation (32-36). It has also been used in the management of autoimmune conditions, including rheumatoid arthritis $(37,38)$. MMF has been studied as an alternate agent in the treatment of both Crohn's disease (39-45) and ulcerative colitis $(45,46)$. A one-year randomized trial comparing AZA and prednisolone with MMF and prednisolone in ulcerative colitis demonstrated increased toxicity of MMF while failing to demonstrate improved efficacy (46). The use of MMF in Crohn's disease has yielded variable results. In patients intolerant of AZA, most studies have demonstrated lack of significant efficacy of MMF (41-46). However, the one randomized trial 


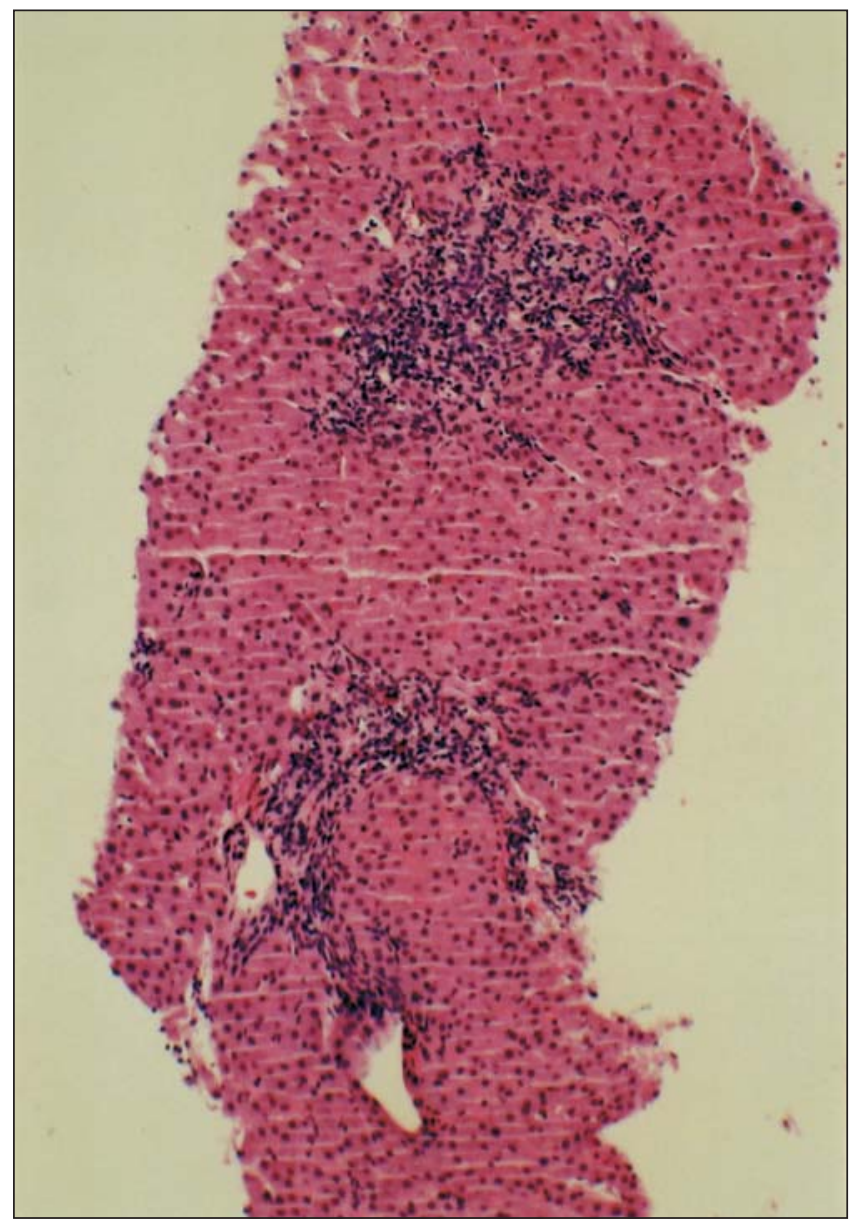

Figure 1) Liver biopsy from case 5 (hematoxylin and eosin stain, original magnification 40x) obtained intraoperatively in January 2002 before starting treatment with mycophenolate mofetil. Serum alanine aminotransferase was normal but portal tracts were expanded with an inflammatory infiltrates composed primarily of lymphocytes and plasma cells (grade 2/4 inflammation). Masson-Trichrome stain revealed periportal (stage 2/4) fibrosis (not shown)

comparing MMF and corticosteroids with AZA and corticosteroids demonstrated similar efficacy of the two treatments (40).

Richardson et al (24) evaluated the use of MMF in seven $\mathrm{AIH}$ patients resistant to or intolerant of standard therapy. Patients were treated with $250 \mathrm{mg}$ of MMF twice daily, escalating to a final dose of $1 \mathrm{~g}$ twice daily. Five patients (71\%) entered biochemical remission with the mean dose of prednisolone falling from $20 \mathrm{mg}$ to $2 \mathrm{mg}$. Liver biopsies were obtained before and after MMF therapy in all patients and the hepatic activity index showed significant improvement after treatment with MMF. The only adverse event seen in this series was dose related leukopenia (24).

In our series, all patients were intolerant of or were not responding to standard therapy with AZA, 6-MP and or prednisone, and to the best of our knowledge, all patients had been compliant with these prescribed therapies. MMF given in doses ranging from $500 \mathrm{mg}$ to $1 \mathrm{~g}$ twice daily resulted in biochemical improvement in all of our patients. Furthermore, MMF resulted in a histological remission in

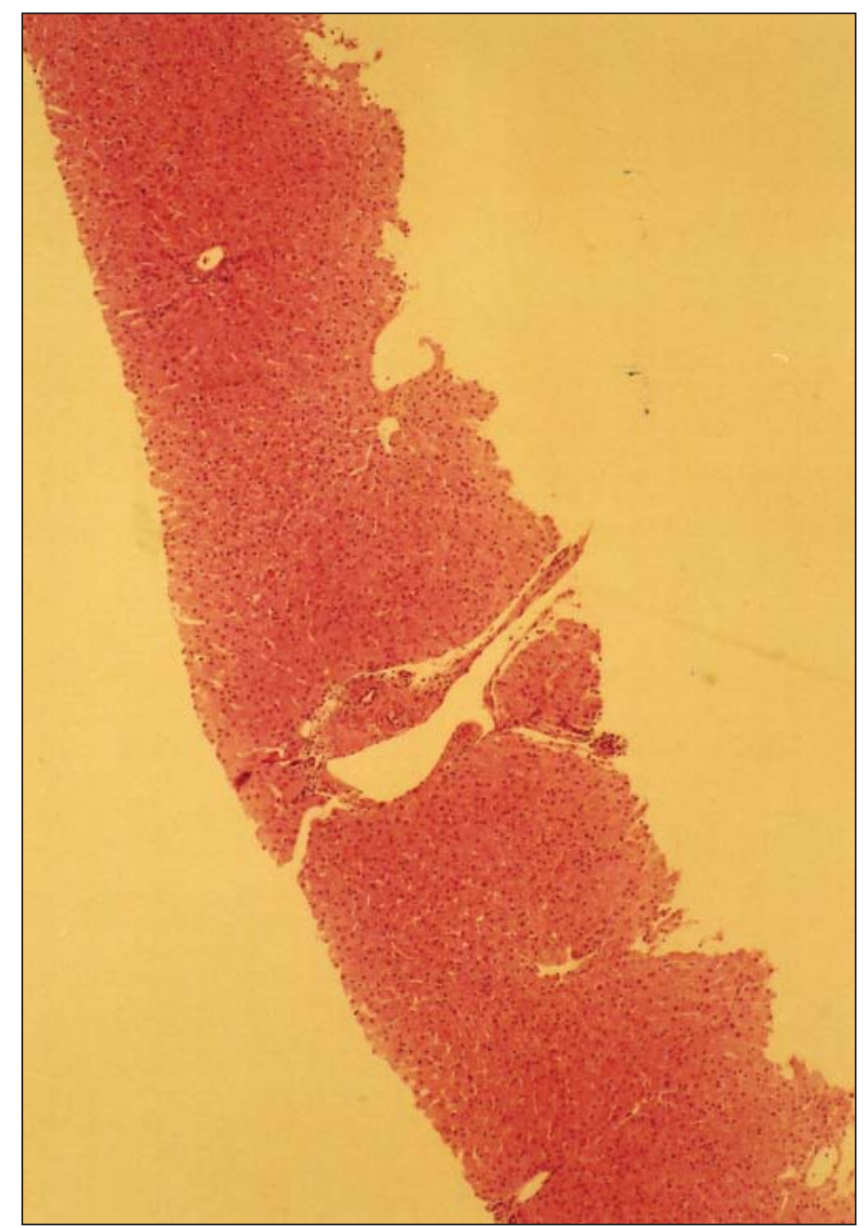

Figure 2) Liver biopsy from case 5 (hematoxylin and eosin stain, original magnification 40x) obtained in January 2003 after seven months of treatment with mycophenolate mofetil. The patient was in histological remission with no significant inflammation (grade 0/4). MassonTrichrome stain revealed less fibrosis (stage 1/4) (not shown)

one patient who had active periportal inflammation on liver biopsy, despite having a normal ALT, while on AZA monotherapy. This patient (case 5) previously had steroidinduced psychosis with suicidal ideation, thereby prohibiting the reintroduction of prednisone. The switch to MMF resulted in a histological remission within seven months and also improved her symptoms of fatigue and arthralgias. This suggests that MMF can induce histological remission alone, without the use of steroids. Follow-up histology was not available in the other four patients within our series, although MMF resulted in clinical and biochemical remission in these patients.

We were also able to demonstrate a steroid-sparing effect with the use of MMF. In all four patients taking corticosteroids we were able to lower the dose of prednisone after initiating MMF. The mean dose of prednisone fell from $21.25 \mathrm{mg} /$ day before MMF to $8.4 \mathrm{mg} /$ day one year after starting MMF. The patient described in case 3 has been successfully weaned from corticosteroids and remains in biochemical and clinical remission on MMF monotherapy. 
Interestingly, we also saw an improvement in a coexisting autoimmune condition in one patient treated with MMF. ITP has successfully been treated with MMF (26), and in the patient in case 4 there was a dramatic improvement in platelet counts from $6 \times 10^{9} / \mathrm{L}$ to $61 \times 10^{9} / \mathrm{L}$, after the introduction of MMF, despite stable doses of prednisone. Another patient with inflammatory bowel disease (case 3) has maintained remission of her Crohn's disease after starting MMF. As stated earlier, the role of MMF for the treatment of inflammatory bowel disease remains unclear. MMF was well tolerated by all patients in our series and we did not see significant leukopenia in any patient.

\section{REFERENCES:}

1. Boberg KM, Aadland E, Jahnsen J, et al. Incidence and prevalence of primary biliary cirrhosis, primary sclerosing cholangitis, and autoimmune hepatitis in a Norwegian population. Scand J Gastroenterol 1998;33:99-103.

2. Boberg KM. Prevalence and epidemiology of autoimmune hepatitis. Clin Liver Dis 2002;6:347-59.

3. Wiesner RH, Demetris AJ, Belle SH, et al. Acute hepatic allograft rejection: Incidence, risk factors, and impact on outcome. Hepatology 1998;28:638-45.

4. Soloway RD, Summerskill WH, Baggenstoss AH, et al. Clinical, biochemical, and histological remission of severe chronic active liver disease: A controlled study of treatments and early prognosis. Gastroenterology 1972;63:820-33.

5. Cook GC, Mulligan R, Sherlock S. Controlled prospective trial of corticosteroid therapy in active chronic hepatitis. Q J Med 1971;40:159-85.

6. Murray-Lyon IM SR, Williams R. Controlled trial of prednisone and azathioprine in active chronic hepatitis. Lancet 1973;1:735-7.

7. Stellon AJ, Keating JJ, Johnson PJ, et al. Maintenance of remission in autoimmune chronic active hepatitis with azathioprine after corticosteroid withdrawal. Hepatology 1988;8:781-4.

8. Johnson PJ, McFarlane IG, Williams R. Azathioprine for long-term maintenance of remission in autoimmune hepatitis. N Engl J Med 1995;333:958-63.

9. Czaja AJ, Freese DK. Diagnosis and treatment of autoimmune hepatitis. Hepatology 2002;36:479-97.

10. Hyams JS, Ballow M, Leichtner AM. Cyclosporine treatment of autoimmune chronic active hepatitis. Gastroenterology 1987;93:890-3.

11. Person JL, McHutchison JG, Fong TL, et al. A case of cyclosporinesensitive, steroid-resistant, autoimmune chronic active hepatitis. J Clin Gastroenterol 1993;17:317-20.

12. Jackson LD, Song E. Cyclosporin in the treatment of corticosteroid resistant autoimmune chronic active hepatitis. Gut 1995;36:459-61.

13. Fernandes NF, Redeker AG, Vierling JM, et al. Cyclosporine therapy in patients with steroid resistant autoimmune hepatitis. Am J Gastroenterol 1999;94:241-8.

14. Sherman KE, Narkewicz M, Pinto PC. Cyclosporine in the management of corticosteroid-resistant type I autoimmune chronic active hepatitis. J Hepatol 1994;21:1040-7.

15. Senturk H. Treatment of corticosteroid-azathioprine resistant autoimmune hepatitis with cyclosporin A. Indian J Gastroenterol 1995;14:110-1.

16. Pratt DS, Flavin DP, Kaplan MM. The successful treatment of autoimmune hepatitis with 6-mercaptopurine after failure with azathioprine. Gastroenterology 1996;110:271-4.

17. Kanzler S, Gerken G, Dienes HP, et al. Cyclophosphamide as alternative immunosuppressive therapy for autoimmune hepatitisreport of three cases. Z Gastroenterol 1997;35:571-8.

18. Czaja AJ, Carpenter HA, Lindor KD. Ursodeoxycholic acid as adjunctive therapy for problematic type 1 autoimmune hepatitis: A randomized placebo-controlled treatment trial. Hepatology 1999;30:1381-6.

19. Czaja AJ, Lindor KD. Failure of budesonide in a pilot study of treatment dependent autoimmune hepatitis. Gastroenterology 2000;119:1312-6.

20. Venkataramani A, Jones MB, Sorrell MF. Methotrexate therapy for refractory chronic active autoimmune hepatitis. Am J Gastroenterol 2001;96:3432-4.
There was one patient who developed pyelonephritis that required hospitalization and intravenous antibiotics, but this did not necessitate the discontinuation of MMF therapy.

Although this present series is limited by the lack of histological follow-up in all patients, we believe it provides further evidence for the role of MMF in patients with AIH refractory to standard therapy. Also, as our series demonstrates, MMF is well tolerated and effective in achieving biochemical remission in AIH patients, and we believe that MMF should be evaluated prospectively as a steroid-sparing agent for the initial treatment of AIH.

21. Burak KW, Urbanski SJ, Swain MG. Successful treatment of refractory type 1 autoimmune hepatitis with methotrexate. J Hepatol 1998;29:990-3.

22. Malekzadeh R, Nasseri-Moghaddam S, Kaviani MJ, et al. Cyclosporin $\mathrm{A}$ is a promising alternative to corticosteroids in autoimmune hepatitis. Dig Dis Sci 2001;46:1321-7.

23. Schuppan D Herold C, Strobel D, Schneider HT, Hahn EG. Successful treatment of therapy-refractory autoimmune hepatitis with mycophenolate mofetil. Hepatology 1998;28:A1960. (Abst)

24. Richardson PD, James PD, Ryder SD. Mycophenolate mofetil for maintenance of remission in autoimmune hepatitis in patients resistant to or intolerant of azathioprine. J Hepatol 2000;33:371-5

25. Alvarez F, Berg PA, Bianchi FB, et al. International autoimmune hepatitis group report: Review of criteria for diagnosis of autoimmune hepatitis. J Hepatol 1999;31:929-38.

26. Howard J, Hoffbrand AV, Prentice HG, et al. Mycophenolate mofetil for the treatment of refractory auto-immune haemolytic anaemia and auto-immune thrombocytopenia purpura. Br J Haematol 2002;117:712-5.

27. Nakamura K, Yoneda M, Yokohama S, et al. Efficacy of ursodeoxycholic acid in Japanese patients with type 1 autoimmune hepatitis. J Gastroenterol Hepatol 1998;13:490-5.

28. Flourey HW, Gilliver K, Jennings MA, Saunder AG. Mycophenolic acid: An antibiotic from Penicillium brevicompactum Dierckx. Lancet 1946;250:46-9.

29. Heneghan MA, McFarlane IG. Current and novel immunosuppressive therapy for autoimmune hepatitis. Hepatology 2002;35:7-13.

30. Vierling JM, Flores PA. Evolving new therapies of autoimmune hepatitis. Clin Liver Dis 2002;6:537-62.

31. Tiede I, Fritz G, Strand S, et al. CD28-dependent Rac1 activation is the molecular target of azathioprine in primary human CD4+ T lymphocytes. J Clin Invest 2003;111:1133-45.

32. Sollinger HW. Mycophenolate mofetil for the prevention of acute rejection in primary cadaveric renal allograft recipients. U.S. Renal Transplant Mycophenolate Mofetil Study Group. Transplantation 1995;60:225-32.

33. Placebo-controlled study of mycophenolate mofetil combined with cyclosporin and corticosteroids for prevention of acute rejection. European Mycophenolate Mofetil Cooperative Study Group. Lancet 1995;345:1321-5.

34. Matthew TH. A blinded, long-term randomized multicenter study of mycophenolate mofetil in cadaveric renal transplantation. Results at three years. Tricontinental Mycophenolate Mofetil Renal Transplantation Study Group. Transplantation 1998;65:1450-4

35. Eckhoff DE, McGuire BM, Frenette LR, et al. Tacrolimus (FK506) and mycophenolate mofetil combination therapy versus tacrolimus in adult liver transplantation. Transplantation 1998;65:180-7.

36. Kobashigawa J ML, Renlund D, Mentzer R, et al. A randomized active controlled trial of mycophenolate mofetil in heart transplant recipients. Transplantation 1998;66:507-15.

37. Schiff MH, Goldblum R, Rees MMC. 2-Morpholino-ethyl mycophenolic acid (ME-MPA) in the treatment of refractory rheumatoid arthritis (RA). Arthr Rheum 1990;33:D126. (Abst)

38. Quiroz Y, Herrera-Acosta J, Johnson RJ, Rodriguez-Iturbe B. Mycophenolate mofetil treatment in conditions different from organ transplantation. Transplant Proc 2002;34:2523-6. 


\section{Devlin et al}

39. Fickert P, Hinterleitner TA, Wenzl HH, et al. Mycophenolate mofetil in patients with Crohn's disease. Am J Gastroenterol 1998;93:2529-32.

40. Neurath MF, Wanitschke R, Peters M, Krummenauer F, Meyer zum Buschenfelde KH, Schlaak JF. Randomised trial of mycophenolate mofetil versus azathioprine for treatment of chronic active Crohn's disease. Gut 1999;44:625-8.

41. Hassard PV, Vasiliauskas EA, Kam LY, et al. Efficacy of mycophenolate mofetil in patients failing 6-mercaptopurine or azathioprine therapy for Crohn's disease. Inflamm Bowel Dis 2000;6:16-20.

42. Fellermann K, Steffen M, Stein J, et al. Mycophenolate mofetil: Lack of efficacy in chronic active inflammatory bowel disease. Aliment Pharmacol Ther 2000;14:171-6.
43. Miehsler W, Reinisch W, Moser G, Gangl A, Vogelsang H. Is mycophenolate mofetil an effective alternative in azathioprineintolerant patients with chronic active Crohn's disease? Am J Gastroenterol 2001;96:782-7.

44. Hafraoui S, Dewit O, Marteau P, et al. [Mycophenolate mofetil in refractory Crohn's disease after failure of treatments by azathioprine or methotrexate.] Gastroenterol Clin Biol 2002;26:17-22. French.

45. Skelly MM, Logan RF, Jenkins D, Mahida YR, Hawkey CJ. Toxicity of mycophenolate mofetil in patients with inflammatory bowel disease. Inflamm Bowel Dis 2002;8:93-7.

46. Orth T, Peters M, Schlaak JF, et al. Mycophenolate mofetil versus azathioprine in patients with chronic active ulcerative colitis: A 12-month pilot study. Am J Gastroenterol 2000;95:1201-7. 


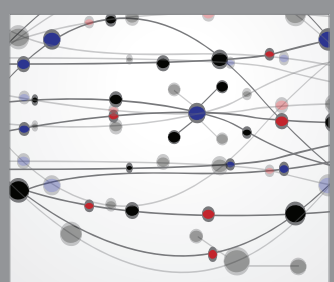

The Scientific World Journal
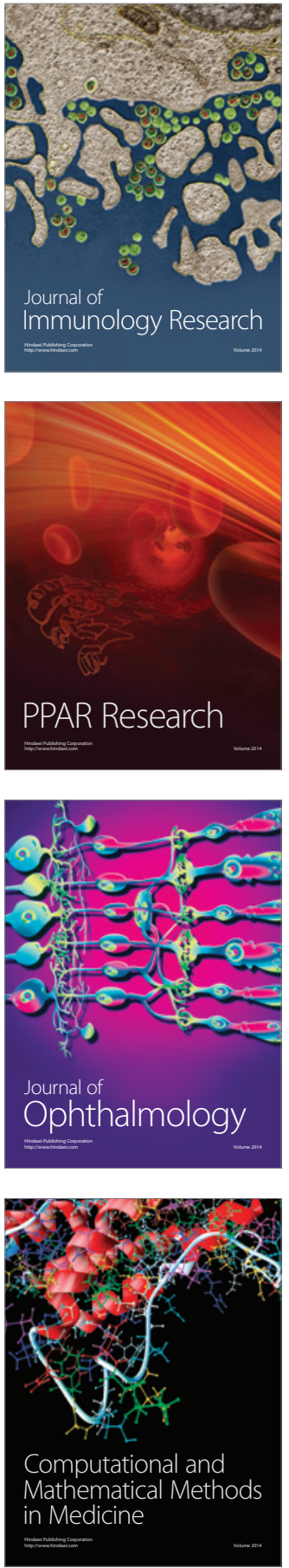

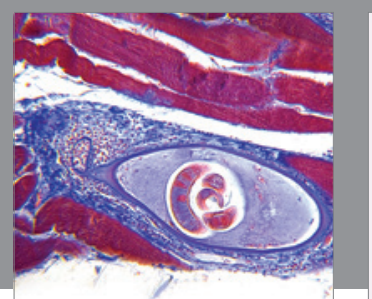

Gastroenterology Research and Practice

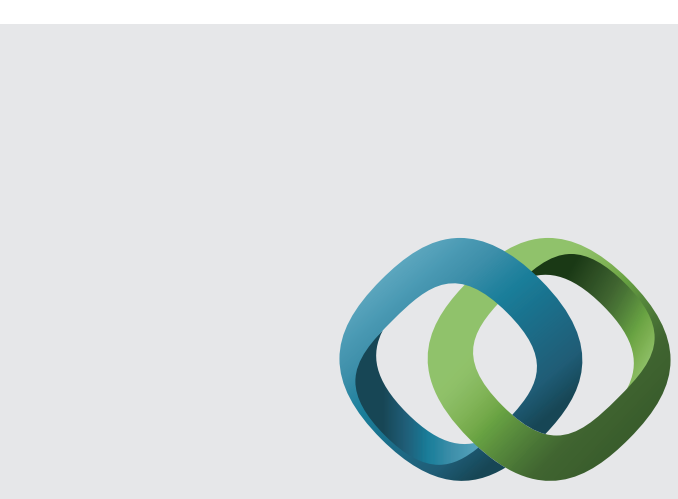

\section{Hindawi}

Submit your manuscripts at

http://www.hindawi.com
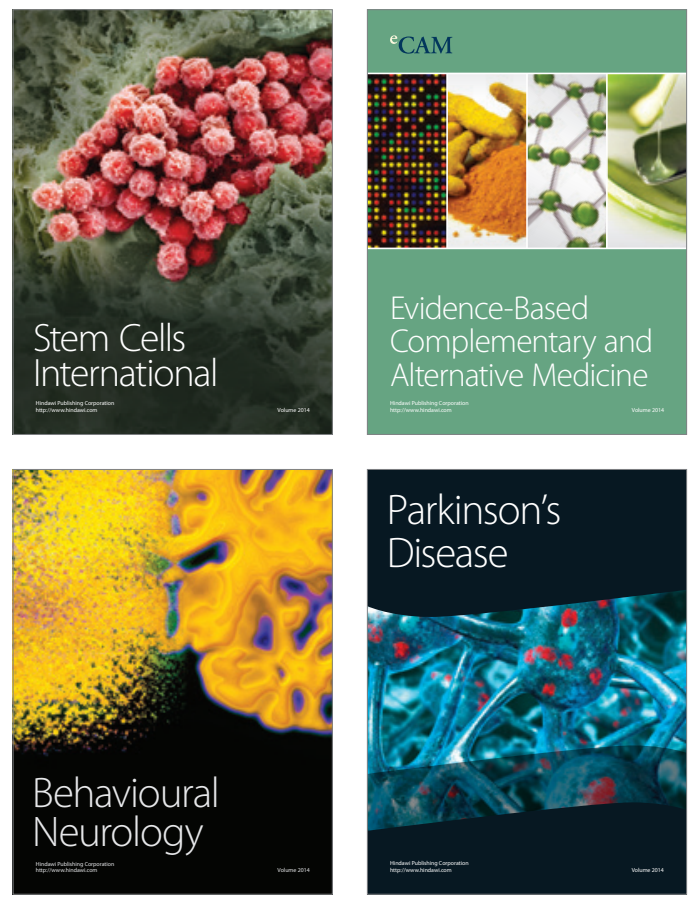
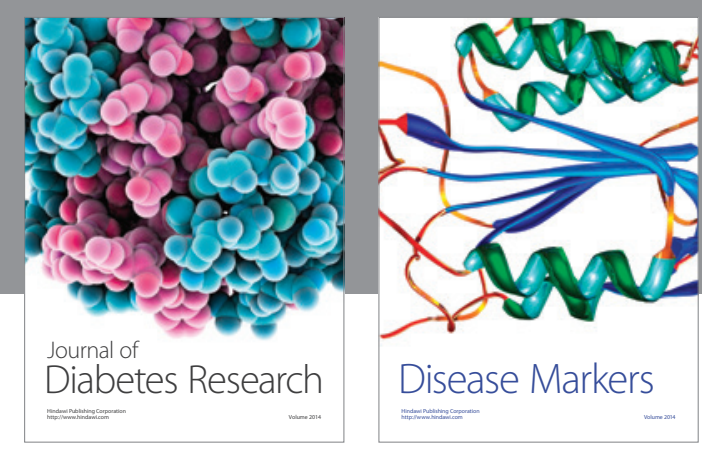

Disease Markers
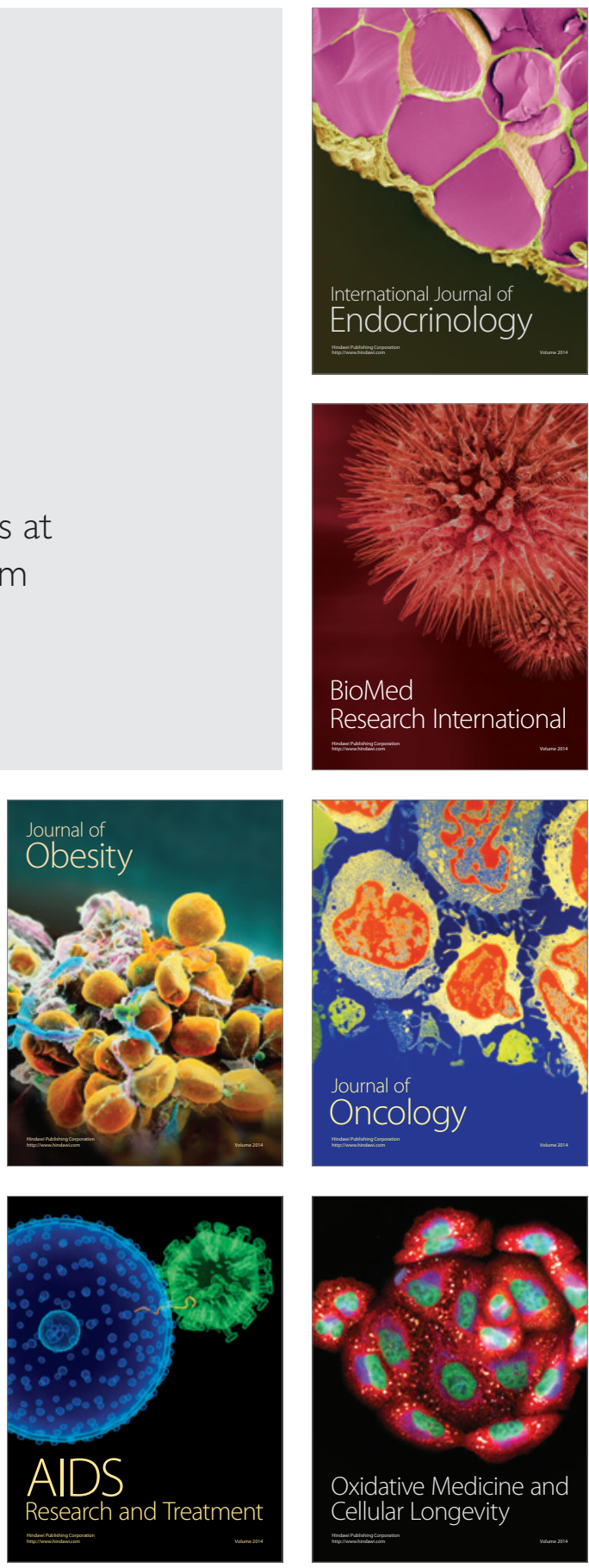